\title{
1 Bird use of grain fields and implications for habitat management at airports
}

2 Raymond B. Iglay $^{\mathrm{a} 1}$, Bruce N. Buckingham ${ }^{\mathrm{b}}$, Thomas W. Seamans ${ }^{\mathrm{b}}$, James A. Martin ${ }^{\mathrm{c}}$, Bradley

$3 \quad$ F. Blackwell ${ }^{\mathrm{b}}$, Jerrold L. Belant ${ }^{\mathrm{a}}$, and Travis L. DeVault ${ }^{\mathrm{b}}$

$4{ }^{a}$ Department of Wildlife, Fisheries, and Aquaculture, Mississippi State University, Box 9690,

5 Mississippi State, MS 39762.

$6 \quad{ }^{\mathrm{b}}$ United States Department of Agriculture, Animal and Plant Health Inspection Service, Wildlife

7 Services, National Wildlife Research Center, 6100 Columbus Avenue, Sandusky, OH, 44870.

$8{ }^{c}$ Warnell School of Forestry and Natural Resources, Savannah River Ecology Lab, The

9 University of Georgia, Warnell 3 Room 320, 180 East Green Street, Athens, GA, 30602.

10 ABSTRACT

11 Airport properties often include agricultural land cover that can attract wildlife species

12 hazardous to aircraft, despite recommendations against row crops near air operations areas.

13 However, few studies have directly quantified bird use of corn, wheat, and soybean fields

14 relative to bird-aircraft collision (strike) hazard levels to support land cover recommendations.

15 Therefore, we compared bird use among corn, wheat and soybean fields and predicted that corn

16 and wheat would attract bird species recognized as hazardous to aviation. We also anticipated

17 that soybeans would pose minimal attraction to such birds. Here, hazard ranking (low to

18 extremely high) reflects the percentage of strikes involving a species that resulted in damage to

19 aircraft. We investigated bird use among 22 corn, wheat, and soybean fields near Oak Harbor,

$20 \mathrm{OH}$, using approximately weekly point transects from 2013 to 2014 . We used generalized

21 distance sampling models and analysis of variance using distance matrices to determine bird

22 abundance and community responses to row crop land coverages and crop height. We observed

234,331 birds of 40 species, with most birds observed in wheat fields ( $n=2,555$ birds) and

\footnotetext{
${ }^{1}$ Corresponding author: Raymond B. Iglay, ray.iglay@msstate.edu; (662) 325-3498
} 
24 standing stubble ( $n=2,409$ birds). Large flocks occurred more in corn and wheat fields than

25 soybean fields, but soybean fields harbored greater cumulative hazard scores than corn, likely

26 due to consistent detections of small, non-flocking birds in soybean fields. Crop type and height

27 had greater influence on medium- and high-hazard level bird species than other hazard levels.

28 Density of medium- and high-hazard level birds increased with increasing crop height in soybean

29 and wheat fields with wheat fields having slightly greater densities than soybeans. Corn fields

30 also had the greatest bird densities in the tallest crop height categories. Categories of very and

31 extremely high-hazard level bird species were rarely detected, but their abundance peaked in

32 crops 0-15 cm, similar to low-hazard level bird species. However, model selection results

33 included null models for very and extremely high-hazard level bird species suggesting minimal

34 effects. Overall, our results suggest that all three crop types can harbor birds hazardous to

35 aircraft, and crop height can enhance bird use. Although not directly tested in our study, land

36 management surrounding airports may benefit most from alternative land covers (e.g., biofuel

37 crops), but additional research is necessary.

38 Key words: airports; birds; corn; hazard mitigation; Ohio; row crop; soybeans; wheat

\section{$39 \quad 1.0$ INTRODUCTION}

Bird composition and abundance in agricultural fields vary throughout the production

41 cycle following changes in food and cover availability. Newly planted fields in the USA can

42 attract open-field, ground-nesting species such as killdeer (Charadrius vociferus; Basore et al.,

43 1986; Cornell Lab of Ornithology, 2013), but lack the protective cover which increases as crops

44 mature (Wilson et al., 1996; Chamberlain et al., 1999; Moorcroft et al., 2002; Kuzmenko, 2012).

45 However, food availability in newly planted or stubble fields can attract myriad bird species

46 despite cover preferences (Fernández-Juricic et al., 2004). After crops mature, cultivation 
47 practices further influence bird communities as they affect crop residue and waste grain

48 availability (Rodenhouse and Best, 1983; Basore et al., 1986; Krapu et al., 2004) and even

49 directly destroy nests or kill birds (Rodenhouse and Best, 1983; Frawley, 1989; Rodenhouse et

50 al., 1993).

Food and cover use varies by crop type as well. For example, corn (Zea mays) comprised

$5245.4 \%$ of fall foods for mourning doves (Zenaida macroura; Chamberlain, 1965), and corn silage

53 and grains comprised 9-16\% and 21-26\%, respectively, of stomach contents in European

54 starlings (Sturnus vulgaris; Killpack and Crittenden, 1952). Snow geese (Chen caerulescens)

55 select waste corn over wheat and soybeans (Frederick and Klass, 1982). Canada goose (Branta

56 canadensis) and other waterfowl have demonstrated differential field use based on waste corn

57 density (Anteau et al. 2011). As cover, fields with standing stubble of cereal crops and oilseed

58 were used by more granivores than fields with traditional tillage in Europe and North America

59 (Castrale, 1985; Donald and Forrest, 1995; Chamberlain et al., 1999; Gillings et al., 2005; Kopij,

60 2008; Kragten and deSnoo, 2008). Sterner et al. (1984) found 28 crops that had no reports of bird

61 use. For example, soybeans may not provide adequate structure and cover for some wildlife

62 species and are a low-quality food for waterfowl (Krapu et al., 2004). However, the lack of

63 reported use does not conclusively demonstrate that birds do not use those crops.

64 Corn and wheat are known attractants and can be used extensively by wildlife (Best et al.

65 1990; Krapu et al., 1995; Cerkel et al., 2009), but limited information is available comparing

66 their use to soybeans (Blackwell and Dolbeer, 2001; Krapu et al., 2004, 2005; Galle et al., 2009).

67 The U.S. Federal Aviation Administration (FAA) recommends against the use of airport property

68 for agricultural production (FAA Advisory Circular 150/5200-33B) and recognizes that most, if

69 not all, crops can attract hazardous wildlife during some phase of production (FAA, 2007). 
70 Wildlife strike risk mitigation at airports is essential for safe air operations (DeVault et al.,

71 2013a). From 1990-2014, wildlife strikes caused 981,200 hours of downtime, $\$ 631.8$ million in

72 direct costs and \$76.4 million for other costs, not including lost revenue, flight cancellations, or

73 passenger accommodations (Dolbeer et al., 2015). However, financial constraints often favor

74 leasing airport land outside primary airport operation areas to farmers, in which case minimum

75 distances between on-airport crops and specific airport features should be maintained (Advisory

76 Circular 150/5300-13, Appendix 17; FAA, 2007). Among 10 small airports in Indiana, USA,

77 land coverage of soybean (10.3\%) and corn (9.5\%) fields were intermediate to short grass (e.g.,

78 airport grassland; 40.2\%) and runway systems (8.1\%; DeVault et al., 2009). Investigating bird

79 use of agricultural crop fields and their potential hazards could inform airport personnel of the

80 associated wildlife strike risk of row crops adjacent to air operations areas and encourage

81 establishment of alternative land uses, including haying, biofuel crops, native warm season

82 grasses, and solar arrays (Blackwell et al., 2009; Martin et al., 2011, 2013; DeVault et al., 2012,

83 2013b, 2014).

$84 \quad$ Mature crops can also restrict bird line of sight, influencing bird predator-evasion

85 behaviors in some species and consequently bird use (Brough and Bridgman, 1980; Conover and

86 Kania, 1991; see also Blackwell et al., 2013, 2016). Flocking bird species in taller and denser

87 vegetation encounter greater visual obstruction which has been observed to increase vigilance

88 and lengthen response times to predator attacks (Devereux et al., 2004; Whittingham and

89 Deverux, 2008). Flock sizes of European starlings can also influence their likelihood of using

90 dense, visually-obstructive vegetation that smaller flocks and individuals may avoid (Fernández-

91 Juricic et al., 2004). Typical airfield grassland management focuses on grass height manipulation

92 to mitigate bird hazards in which taller, visually obstructive grass heights (i.e., obstructive to 
93 most passerines) might be less attractive to some, large-bodied bird species than short grass.

94 Shorter grass heights also support visual detection of potential hazards (i.e., detecting hazardous

95 animals approaching active runways). Currently, the FAA does not have a direct policy

96 regarding grass height recommendations for wildlife hazard mitigation at airports but instead

97 advises development of local grass-management plans incorporating airport-specific

98 characteristics such as local hazardous species (FAA, 2009).

99 Most research regarding bird use and agriculture has compared bird use among

100 conservation practices or alternative field management practices of single crop types (e.g., till vs.

101 no-till) and seldom includes direct comparisons of bird use among traditionally managed row

102 crop and concomitant changes in crop height. To accurately assess potential hazard risk of

103 traditional row cropping near airports and vegetation height management, it is essential to

104 conduct direct comparisons of bird field use and assess hazard associated with each crop type

105 and height. Bird field use can also differ among ecological regions emphasizing the need to

106 investigate region-specific responses for developing optimal conservation or hazard mitigation

107 management (Whittingham et al., 2008; however, we do address avian field use at this scale.

108 The aim of our study was to compare bird use among crops (corn, soybeans, and wheat)

109 and crop heights that are commonly planted on and near U.S. airports, especially smaller,

110 General Aviation airports and determine whether abundance of birds hazardous to aircraft differs

111 among crop types and heights (DeVault et al. 2009, 2013b). Based on past research and

112 observations, we predicted greater use of corn and wheat fields by bird species recognized as

113 hazardous to aviation (see below) and anticipated that soybeans would pose minimal attraction to

114 such birds. However, we also predicted declining hazard risk as each crop grew and crop height

115 increased. The FAA Wildlife Strike Database provides extensive information about bird-aircraft 
116 collisions since 1990 (Dolbeer et al., 2015). Some information recorded per strike includes

117 species struck, any effects on flight, recordable damage, repair costs, and number of birds struck.

118 From this information, Dolbeer and Wright (2009) developed species-specific hazard-level

119 categories for bird-aircraft collisions (low: $\leq 1 \%$ of strikes causing damage to extremely high

120 hazard: $\geq 40 \%$ of strikes causing damage). DeVault et al. (2011) further refined hazard-level

121 categories by ranking species according to strike history information such as percentage of total

122 strikes that caused any level of aircraft damage, substantial damage, or that otherwise affected

123 flights. We assigned bird species to hazard-level categories developed by Dolbeer and Wright

124 (2009) to assist with the evaluation of wildlife strike concern among crop types and heights. We

125 also calculated the product of each species or species-group's hazard score and count per field

126 visit using hazard scores from DeVault et al. (2011). Then, we summed the products among

127 species or species-group per field visit to generate a cumulative hazard metric.

$128 \quad 2.0$ MATERIAL AND METHODS

$129 \quad 2.1$ Study Area

130 We sampled 22 agricultural fields near Oak Harbor, OH from June 2013 to March 2014

131 (Figure 1). Large populations of blackbirds and waterfowl have been observed in this area due to

132 the close proximity of Lake Erie and associated marshes. For example, during fall 2013, the Ohio

133 Department of Natural Resources counted between 1,000 - 6,000 Canada geese in the region (M.

134 Ervin, Ohio Department of Natural Resources, unpublished data). Fields were approximately 5-

$13525 \mathrm{ha}(\bar{x}=12.4 \mathrm{ha}, \mathrm{SE}=1.04 \mathrm{ha})$ and $<0.25-3.0 \mathrm{~km}$ apart $(\bar{x}=1.69 \mathrm{~km} \pm 0.16 \mathrm{~km})$. Fields were

136 planted in corn $(n=3)$, wheat $(n=8)$, or soybeans $(n=11)$ for both study years. Our initial, more

137 balanced design was disrupted by fields not being rotated [corn to soybeans $(n=5)$ or soybeans 
138 to corn $(n=3)$ ] as we anticipated during study began. We were also restricted to sampling from

139 field edges.

$140 \quad$ 2.2 Sampling Methods

141 We observed birds about weekly ( $n=42$ visits) for 3 minutes from a single, permanent

142 sampling point on each field's edge using one observer for all observations. We recorded all

143 birds detected within or above each field (i.e., approximately crop height), their distance from the

144 observer (ocular estimate), species, flock or group size (count), detection type (visual or aural),

145 and time of detection (Buckland et al., 2001). Numerous factors can affect field use by birds such

146 as condition or energetic state, and food and cover resources. We assumed crop type represented

147 food resources. Despite crop height indicating food availability with regards to crop maturity,

148 such as stubble harboring greater waste grain food resources than actively growing crops, we

149 used crop height, however, to primarily represent cover resources. We measured vegetation

150 height during each visit $(\mathrm{cm})$ but represented crop stubble as a qualitative variable. We then

151 developed two crop-height classifications to investigate bird use between crop heights, one

152 representing past research regarding typical airfield grassland management approaches (e.g.,

153 airport grassland height) and the second based on hypotheses regarding bird predator avoidance

154 behaviors (e.g., bird eye height; sensu Blackwell et al. 2013). We developed the airport

155 grassland-height classification from literature documenting bird use in and around airports

156 (height bins: 0-15 cm [Mead and Carter, 1973; Brough and Bridgman, 1980; Buckley and

157 McCarthy, 1994; Seamans et al., 1999; Seamans et al., 2007]; >15-25 cm [Mead and Carter,

158 1973; Brough and Bridgman, 1980; Transport Canada, 1994; Dekker and van der Zee, 1996;

159 Barras et al., 2000; Washburn and Seamans, 2004; Seamans et al., 2007]; >25-45 cm [Seamans

160 et al., 1999]; >45 cm [Buckley and McCarthy, 1994; considered "unmanaged" grass by Barras et 
161 al., 2000]). To represent the FAA's recommendation and bird predator avoidance behaviors as

162 they pertain to increasing crop height, we categorized measured heights based on average body

163 lengths of observed ground foraging bird species, with bird lengths obtained from the Cornell

164 Lab of Ornithology (2013). Although bird length may only be a proxy for eye height, it was

165 readily available and provides a metric for comparison. Finally, we retained our stubble height

166 category for each height classification approach.

\section{$167 \quad 2.3$ Analysis}

168 We investigated bird abundance responses to crop type and height using the generalized 169 distance sampling model of Royle et al. (2004) and Chandler et al. (2011) with the "gdistsamp"

170 function of R package unmarked (R Core Team, 2015). Generalized distance sampling models

171 expand upon distance sampling analyses by not only allowing for inference about population

172 densities of unmarked individuals but also accounting for temporary emigration and imperfect

173 detection. We used month as our primary time period and calculated average crop height by

174 month before segregating crop heights by height classification (see previous paragraph). To

175 ensure crop height responses were driven by bird crop height selection and not seasonality of

176 bird behavior, we checked linear and non-linear correlation between crop height and month using

177 Pearson's product-moment correlation with the "cor.test" function and generalized additive

178 models with "gam" function in R package stats (R Core Team, 2015). Linear relationships were

179 weak $(r=0.0961)$, but a non-linear trend was significant $\left(\mathrm{t}\right.$-value $\left.=19.53, P<0.001, \mathrm{R}^{2}=0.214\right)$

180 with increasing crop height from April through August, then decreasing until January. However,

181 this pattern does not reflect bird seasonal patterns of migration and nesting, suggesting that any

182 crop-height effects would result from bird crop-height selection. We categorized bird species by

183 hazard level (Dolbeer and Wright, 2009) which also increased detections per response variable 
184 (i.e., observations of individual birds or flocks) and developed time-series covariates for crop

185 type and height for estimating abundance to account for monthly changes. We assumed detection

186 among species within hazard level would be similar because hazard level typically increases with

187 bird body size and flocking behavior (DeVault et al., 2011). Due to low detections (<30

188 detections), we combined bird detections in 'very high' and 'extremely high' bird hazard levels

189 (Dolbeer and Wright, 2009). We developed models of all combinations of abundance covariates

190 per hazard category and a model with no covariates. We evaluated all models using Akaike's

191 Information Criterion adjusted for small sample sizes $\left(\mathrm{AIC}_{\mathrm{c}}\right), \Delta \mathrm{AIC}_{\mathrm{c}}$ values, Akaike weights, and

192 evidence ratios (Burnham and Anderson, 2002). We used $\mathrm{AIC}_{\mathrm{c}}$ model selection to determine the

193 best starting point among half-normal, hazard rate, and uniform key functions and applied the

194 appropriate key function to remaining models (Thomas et al., 2010). Because crop height might

195 affect detection, we tested the effects of month and crop height on bird availability and detection,

196 respectively, in the global model and retained these covariates if model fit improved. We tested

197 data dispersion using results of a Poisson generalized linear model with crop type and height as

198 primary factors with the "dispersiontest" function in R package AER. When data were

199 overdispersed, we used a Negative Binomial mixture, but otherwise used a Poisson mixture.

200 Because crop height classifications were dependent on the same measured variable (e.g., crop

201 height), we developed two model sets per hazard category, one set for each height classification.

202 We summed model weights of predictor variables to assess their relative importance (Burnham

203 and Anderson, 2002). We generated model-averaged hazard level density estimates (lambda) and

204 their 95\% confidence intervals for each predictor variable based on the entire set of models using

205 the "predict" function in unmarked (Burnham and Anderson, 2002). We used model averaging 
among all candidate models due to model selection uncertainty and our interest in understanding

207 the influence of each predictor variable on bird field use.

208 We conducted an analysis of variance using distance matrices (ADONIS) to further

209 investigate bird community responses among crop types and height classifications (Anderson,

210 2001; Ott and Longnecker, 2010) and as an alternate support for distance analysis. Using

211 ADONIS, we partitioned sources of variation while fitting linear models to distance with

212 permutation tests as pseudo- $F$ ratios (Anderson, 2001). We accounted for repeated measures of

213 each field (strata = field) and tested homogeneity of group spread, similar to homogeneity of

214 variance for analysis of variance assumption. using function “betadisper” in R package vegan.

215 We created a species abundance matrix organized by site, month, crop type and each height

216 classification. We investigated interactions of crop type and height using 999 permutations and

217 Bray-Curtis distances (Oksanen, 2014; R Core Team, 2015). We used Bonferroni correction for

218 all ADONIS with an a priori significance level of significance of $\alpha=0.05$ (Ott and Longnecker,

219 2010).

220 We used cumulative hazard score; species richness; and Shannon's diversity to further

221 interpret bird community differences. We calculated relative hazard score per visit (i.e., point

222 transect) as the sum of each detected species' count multiplied by the species' respective hazard

223 score. Then, we summed the products among species or species-group per field visit to generate

224 a cumulative hazard metric. We used species-specific hazard scores to develop a quantitative

225 index of hazard by field risk, not pooling species detections by hazard category. Respective

226 hazard scores were derived from strike report information recorded in the Federal Aviation

227 Administration's Wildlife Strike Database which extend Dolbeer and Wright's (2009) categories

228 by considering percentage of total strikes that caused any level of aircraft damage or substantial 
damage or strikes that affected flights. We assigned each species a hazard score based on

230 DeVault et al. (2011) and applied sparrows' hazard score to unidentified small bird species.

\section{$231 \quad 3.0$ RESULTS}

We observed 4,331 birds of 40 species among soybean, wheat, and corn fields with most

233 birds in wheat fields ( $n=2,555$ birds) and standing stubble of all crops ( $n=2,409$ birds). Of

234 these species, body lengths of 22 ground foragers suggested 3 crop height bins of $0-15 \mathrm{~cm},>15-$

$23532 \mathrm{~cm}$, and $>32 \mathrm{~cm}$, similar to airport grassland height bins (Table 1). The $>45 \mathrm{~cm}$ height

236 category of airport grassland research height classification only occurred for corn, limiting

237 comparisons among crops but also offering insight to potential tall crop attraction. Our most

238 extreme observations occurred in wheat and corn fields. Flocks of 600 common grackles, 400,

239230 and 126 European starlings, and over 100 red-winged blackbirds were observed in wheat

240 fields during September and October. In August and September, tall corn $(>45 \mathrm{~cm})$ fields had

241 flocks of over 300 red-winged blackbirds or barn swallows. Corn and wheat crops also averaged 242 greater group sizes $($ corn $=19.65$ birds, $\sigma=65.51$, wheat $=13.44$ birds, $\sigma=59.91$, soybean $=$

$243 \quad 3.12$ birds, $\sigma=7.69)$.

244 Crop type and height had greater influence on medium and high hazard level bird species

245 than other hazard levels despite crop height classification (Tables 2 and 3). Density of medium

246 and high hazard level birds increased with increasing crop height in soybean and wheat fields

247 with wheat fields having slightly greater densities than soybeans when crop height was based on

248 bird length categories (Table 4). Medium and high hazard level bird densities among grass

249 management crop height classification were greatest in the tallest height category for each crop

250 in addition to slightly greater densities when crops were $0-15 \mathrm{~cm}$ tall compared to stubble and

$251>25-45 \mathrm{~cm}$ crops (Tables 4 and 5). Crop-height only models for low-hazard level birds were 
252 nearly 4 times stronger than second-ranked models of crop-type and height models or crop type

253 only for bird length and grass-management-height classifications, respectively. Whereas, very

254 and extremely high hazard-level birds were rarely detected, but their abundance peaked in crops

$255 \quad 0-15 \mathrm{~cm}$, similar to low hazard-level birds. However, model selection results included null

256 models for very and extremely high hazard-level bird species suggesting minimal effects.

257 Bird communities differed among crops (airport grassland $F_{2,231}=3.12, P$-value $\leq 0.001$,

258 bird length $F_{2,232}=3.94, P$-value $\left.\leq 0.001\right)$ and crop heights (airport grassland $F_{4,231}=5.93, P$ -

259 value $\leq 0.001$, bird length $F_{3,232}=6.70, P$-value $\left.\leq 0.001\right)$. Although differences occurred within

260 most pairwise comparisons, minimal variance was explained by any model (partial $\mathrm{R}^{2}<0.10$,

261 Table 6). According to additional bird community characteristics, diversity metrics and

262 cumulative hazard score increased from corn to wheat (Table 7). Diversity metrics were greater

263 in 0-15 cm crops than other crop heights but biased low (Figure 2), and greater cumulative

264 hazard scores occurred in crops $>32-45 \mathrm{~cm}$ than shorter crops or tall corn $(>45 \mathrm{~cm}$, Figure 2).

\section{4.0 DISCUSSION}

266 Corn, wheat, and soybean fields can harbor birds hazardous to aircraft, and crop height

267 can influence bird use. Corn and wheat fields harbored the most extreme observations regarding

268 flock sizes of hazardous species, but soybean fields were intermediate among corn and wheat

269 fields for cumulative hazard score. Crop type and height can interact to affect bird abundance

270 (see Blackwell et al. 2016), especially for medium and high hazard-level bird species, and

271 increasing crop height harbored greater bird densities. Even soybean fields demonstrated bird

272 densities intermediate to corn and wheat fields when crop heights peaked.

273 The most common species observed among crop fields, European starlings $(n=530$

274 individuals) and red-winged blackbirds ( $n=171$ individuals), were more abundant in wheat 
275 stubble and are known to feed on wheat in addition to corn (Dolbeer et al., 1978; Williams and

276 Jackson, 1981; Linz et al., 2007). Though current harvest methods reduce waste grain (food)

277 availability (Krapu et al. 2004), starlings and blackbirds used standing stubble fields most, likely

278 because of food availability (Gliem et al., 1990; Blackwell et al., 2013). We did not measure

279 food availability, but instead used crop height as an index of available cover. European starlings

280 tend to prefer short vegetation $(13 \mathrm{~cm})$, but larger flocks; as observed in standing stubble and

281 during late summer, suggest managing for visual obstruction alone would not deter starling use

282 (Fernández-Juricic et al., 2004; Blackwell et al., 2013).

283 Growing or harvested soybean fields are generally used less by geese, red-winged

284 blackbirds, northern pintails (Anas acuta), Sandhill cranes (Gus canadensis), and multiple

285 songbirds than wheat or corn fields (Blackwell and Dolbeer, 2001; Krapu et al., 2004, 2005;

286 Galle et al., 2009). Galle et al. (2009) also observed fewer blackbirds in soybean fields and

287 attributed differences to soybean digestibility (Dabbert and Martin, 1994) and lack of protective

288 cover after harvest (Castrale, 1985). However, cumulative hazard scores for soybean fields were

289 greater than corn fields, a possible result of consistent, multiple detections of horned lark

290 (Eremophila alpestris, $n=85$ detections) and killdeer ( $n=42$ detections), low hazard-level

291 species.

292 Birds did not demonstrate field avoidance due to crop heights greater than their line-of-

293 sight. Increasing crop height from 0-45 cm corresponded to increasing abundance of medium and

294 high hazard-level birds. Average measured crop height (i.e., all non-stubble crop heights, $\bar{x}=$

$29547.8 \mathrm{~cm}, \sigma=56.7)$ was greater than lengths of most ground foragers except Canada goose $(\bar{x}=$

$29693.0 \mathrm{~cm}$ ), supporting past research that tall vegetation management is not a panacea for reducing

297 bird use in and around airports, especially when food is available (Fernández-Juricic et al., 2004; 
298 Seamans et al., 2007; Blackwell et al., 2013). For example, migrants including blackbirds and 299 waterfowl often use corn fields as stopovers to forage during fall or spring migration (Krapu et

300 al., 2004; Sawin et al., 2006), whereas breeding birds may focus on cover availability or 301 alternative food such as insects (Blackwell et al., 2013). However; crop heights $>45 \mathrm{~cm}$ only 302 occurred in corn fields.

303 Corn is often considered attractive to many bird species hazardous to aircraft, especially 304 when waste grain is available (Best et al., 1990; Best, 2001; Krapu et al., 2004). But, greater 305 cumulative hazard scores were more frequent in growing fields despite crop type (crops $>25 \mathrm{~cm}$ 306 height), field conditions that often have less available waste grain than standing stubble (Krapu 307 et al., 2004). We observed similar species in corn fields as those designated as occasional or 308 residents by Best and colleagues (1990) during the breeding season. Low- and medium-hazard 309 species (e.g., killdeer, horned larks, mourning doves, red-winged blackbirds) have been observed 310 nesting in corn and soybean fields (Best, 1986; Best et al., 1990; Jorgensen et al., 2009; VanBeek 311 et al., 2014). Substantial nesting habitat loss in Ohio for many facultative grassland bird species 312 over the past century may elevate the importance of alternative, lower quality nesting habitat 313 such as row crop fields (Peterjohn, 1989). Crop height's effect on bird use may also diminish as 314 more nesting birds seek visually-obstructive cover in alternative habitats such as corn, wheat or 315 soybean fields, and are less selective among similar vegetation types (Brough and Bridgman, 316 1980; Conover and Kania, 1991). Hence, some row crops could continue to attract birds 317 hazardous to aircraft throughout the year despite crop height.

318 Six of our 10 most commonly detected bird species were insectivores and contributed 319 most to cumulative hazard ranking. European starlings ranked $40^{\text {th }}$ among 66 bird species 320 involved in wildlife strikes based on percentage of total strikes causing any level of damage; or 
321 an effect on flight; tied $47^{\text {th }}$ of 77 when bird and mammal species were combined (DeVault et al., 322 2011). With the exception of "blackbirds" (65 g), only larger-bodied birds and mammals ranked

323 higher (European starlings = 82 g; DeVault et al., 2011). However, European starlings and

324 blackbirds have contributed to at least 4,940 strikes (1990-2014), with damage reported in 206

325 strikes, negative effects on flight for 262 strikes, with $33 \%$ of strikes involving multiple birds, 326 and with costs totaling $\$ 8,533,151$ (Dolbeer et al., 2015).

327 Nearly a quarter of all bird strikes $(\bar{x}=24.6 \%, \sigma=18.9 \%)$ evaluated by DeVault et al.

328 (2011) involved multiple birds (36.1\% of strikes with birds $\leq 82 \mathrm{~g}$ and $19.6 \%$ of strikes with

329 birds $>82 \mathrm{~g}$ ), and the greatest aerial catastrophe (e.g.; 62 human fatalities) also involved a flock

330 of 200 European starlings in 1960 (Dolbeer 2013). Smaller birds $(\leq 82 \mathrm{~g}$ ) account for $\sim 2,000$

331 fewer bird strikes than larger birds (> $82 \mathrm{~g})$; but aircraft often encounter multiple smaller birds $(\bar{x}$

$332=36.1 \%, \sigma=20.5 \%$ vs. $\bar{x}=19.6 \%, \sigma=15.7 \%$; DeVault et al., 2011). Therefore, smaller

333 flocking birds could pose greater future wildlife strike risk (e.g., frequency of strikes, damage,

334 costly downtown of damaged aircraft) despite only $9 \%$ of all bird strikes typically causing

335 damage (Dolbeer et al., 2015). Row crops around air operations areas, especially corn or wheat 336 crops, could increase this strike risk.

$337 \quad$ For example, flocking behavior contributes less to hazard scores than body mass

338 (DeVault et al., 2011), but small-bodied ( $<1 \mathrm{~kg}$ ), flocking birds could pose greater wildlife strike

339 risk as populations increase and concentrate within urban areas such as airport landscapes (Linz

340 et al., 2007). European starlings, red-winged blackbirds, killdeer, and common grackles were the

341 most frequent species observed during visits with greater than 100 cumulative hazard rate. We

342 observed average flock sizes for European starlings, blackbirds, and grackles of 82, 47, and 16,

343 respectively, with 2 killdeer ever observed together. Red-winged blackbird flocks can shift from 
344 small groups of breeding birds in summer to million plus winter communal roosts with other

345 species (Yasukawa and Searcy, 1995). Communal roosts of starlings and common grackles peak

346 from June to November, often exceeding 2,000 birds (Caccamise et al., 1983). From these

347 communal centers, starlings have been observed dispersing up to 50 miles to foraging areas such

348 as row crop fields (Hamilton and Gilbert, 1969) and even establish diurnal activity centers

349 (Morrison and Caccamise, 1990). As urban dwellers, European starlings, red-winged blackbirds

350 and common grackles will likely continue to thrive on airports and in surrounding urban settings

351 occupying air and ground space in and around air operations (Linz et al., 2007). Agricultural

352 crops could exacerbate the likelihood of their presence and consequent damage potential by

353 increasing the attractiveness of airport areas as diurnal activity centers during late summer and

354 early fall (Dolbeer, 1990; Morrison and Caccamise, 1990). The largest flocks observed in this

355 study occurred in corn and wheat fields and were mostly small-bodied species (e.g., European

356 starlings, common grackles, and red-winged blackbirds). Average group size (e.g., birds

357 observed in groups, not separate individuals) was also 4-6 times greater in corn and wheat fields,

358 respectively, than soybean fields. Therefore, despite greater cumulative hazard scores in soybean

359 fields than corn fields, presence of larger flocks in corn and wheat fields is of greater concern for 360 aircraft safety than non-flocking nesting birds in soybean fields.

\section{$361 \quad 5.0$ CONCLUSIONS}

362 Though larger-bodied animals often rank as greater threats to aircraft, smaller flocking

363 birds can be equally hazardous (Dolbeer, 2013). Smaller birds typically cause less damage or

364 chance of damage, but increasing population densities around and within air operation areas

365 could substantially increase the frequency of strikes with smaller birds. Airports within the

366 northern, Midwest region seeking alternative revenue sources for outlying property should be 
367 wary of row crops, especially corn and wheat, considering surrounding landscapes will continue

368 to have an effect on local bird use and flocking behavior (e.g., communal roosting sites, crop

369 types in surrounding agricultural fields, e.g., Fischl and Caccamise, 1985). However, more

370 research is needed throughout the region among different species contexts and landscape

371 matrices. Concomitant observations of row crops, airport grasslands and alternative land

372 coverages (e.g., native warm season grasses, biofuel crops) could help inform airports of optimal

373 land management approaches to mitigate wildlife strikes (Martin et al., 2011; Martin et al.,

374 2013).

375 ACKNOWLEDGEMENTS

376 We thank the U.S. Federal Aviation Administration and U.S. Department of Agriculture for

377 funding our research. Opinions expressed in this study do not necessarily reflect current Federal

378 Aviation Administration policy decisions regarding the control of wildlife on or near airports.

379 We also thank Jeffrey W. Jones and Laura A. Tyson for their assistance in the field.

380 LITERATURE CITED

381 Anderson, M. J. 2001. A new method for non-parametric multivariate analysis of variance.

$382 \quad$ Austral Ecol. 26; 32-46.

383 Anteau, M. J., Sherfy, M. H., Andrew, A. B., 2011. Location and agricultural practices influence 384 spring use of harvested cornfields by cranes and geese in Nebraska. J. Wildlife Manage. $385 \quad 75,1004-1011$.

386 Barras, S.C., Dolbeer, R., Chipman, R.B., Bernhardt, G.E., Carrara, M.S., 2000. Bird and small 387 mammal use of mowed and unmoved vegetation at John F. Kennedy international airport, 388 1998-1999. Proc. Vertebr. Pest C. 19, 31-36. 
Basore, N.S., Best, L.B., Woodey, J.B., 1986. Bird nesting in Iowa no-tillage and tilled cropland. J. Wildlife Manage. 50, 19-26.

391 Best, L.D., 1986. Conservation tillage: ecological traps for nesting birds? Wildlife S. Bull. 14, 308-317.

Best, L.B., Whitmore, R.C., Booth, G.M., 1990. Use of cornfields by birds during the breeding season: the importance of edge habitat. Am. Midl. Nat. 123, 84-99.

Best, L.B., 2001. Temporal patterns of bird abundance in cornfield edges during the breeding season. Am. Midl. Nat. 146, 94-104.

Blackwell, B.F., DeVault, T.L., Fernández-Juricic, E., Dolbeer, R.A., 2009. Wildlife collisions with aircraft: a missing component of land-use planning for airports. Landscape Urban

Blackwell, B.F., Dolbeer, R.A., 2001. Decline of the red-winged blackbird population in Ohio correlated to changes in agriculture (1965-1996). J. Wildlife Manage. 65, 661-667.

Blackwell, B.F., Seamans, T.W., Linnell, K.,Kutsch-Bach Brohl, L., DeVault, T.L. 2016. Effects

Blackwell, B.F., Seamans, T.W., Schmidt, P.M., DeVault, T.L., Belant, J.L., Whittingham, M.J., Martin, J.A., Fernandez-Juricic, E., 2013. A framework for managing airport grasslands and birds amidst conflicting priorities. Ibis 155, 199-203. of visual obstruction, prey resources, and satiety on bird use of simulated airport grasslands. App. Anim. Behav. Sci. 185, 113-120. 
Buckland, S.T., Anderson, D.R., Burnham, K.P., Laake, J.L., Borchers, D.L., Thomas, L., 2001. Introduction to distance sampling: estimating abundance of biological populations. Oxford University Press, New York, New York, USA.

413 Buckley, P.A., McCarthy, M.G., 1994. Insects, vegetation, and the control of laughing gulls 414 (Larus atricilla) at Kennedy International Airport, New York City. J. Appl. Ecol. 31, 291-302.

416 Burnham, K.P., Anderson, D.R., 2002. Model selection and multinomial inference: a practical information-theoretic approach. Second edition. Spring, New York, USA.

418 Caccamise, D.F., Lyon, L.A., Fischl, J., 1983. Seasonal patterns in roosting flocks of starlings and common grackles. Condor, 474-481.

420 Castrale, J.S., 1985. Responses of wildlife to various tillage conditions. T. N. Am. Nat. Res.C. $50,142-156$.

422 Cerkal, R., Vejrazka, K., Kamler, J., Dvorak, J., 2009. Game browse and its impact on selected 423 grain crops. Plant Soil Environ.55, 181-186.

424 Chamberlain, D.E., Wilson, J.D., Fuller, R.J., 1999. A comparison of bird populations on organic 425 and conventional farm systems in southern Britain. Biol. Conserv. 88, 307-320.

426 Chamberlain, J.L., 1965. Fall foods of Mourning Doves in central Virginia. Wilson Bull. 77: 84$427 \quad 86$.

428 Chandler, R.B., J. A. Royle, King, D.I., 2011. Inference about density and temporary emigration 429 in unmarked populations. Ecology 92: 1429-1435.

430 Conover, M.R., Kania, G.S., 1991. Characteristics of Feeding Sites Used by Urban-Suburban 431 Flocks of Canada Geese in Connecticut. Wildlife S. Bull. 19: 36-38. 
432 Cornell Lab of Ornithology. 2013. All about birds. Retrieved November, 2012 from

433 http://www.allaboutbirds.org/Page.aspx?pid=1189 (accessed 11.02.15).

434 Dabbert, C.B., Martin, T.E., 1994. Effects of diet composition and temperature on food choice of 435 captive mallards. Southwest. Nat. 39:143-147.

436 Dekker, A., Zee, F.F.v.d., 1996. Birds and grasslands on airports. Proc. of the International Bird 437 Strike Committee 23, 291-305.

438 DeVault, T.L., Begier, M.J., Belant, J.L., Blackwell, B.F., Dolbeer, R.A., Martin, J.A., Seamans, T.W., Washburn, B.E., 2013b. Rethinking airport land-cover paradigms: agriculture, grass, and wildlife hazards. Hum. Wildlife Interact. 7, 10-15.

441 DeVault, T.L., Belant, J.L., Blackwell, B.F., Seamans, T.W., 2011. Interspecific variation in wildlife hazards to aircraft: implications for airport wildlife management. Wildlife S.

444 DeVault, T.L., Belant, J.L., Blackwell, B.F., Martin, J.A., Schmidt, J.A., L. W. Burger, J., 2012. Airports offer unrealized potential for alternative energy production. Environ. Manage 49, 517-522.

447 DeVault, T.L., Blackwell, B.F., Belant, J.L., (Eds.), 2013a. Wildlife in Airport Environments: Preventing Animal-Aircraft Collisions through Science-Based Management. Johns Hopkins University Press, Baltimore, Maryland.

DeVault, T.L., Kubel, J.E., Rhodes, O.E., Jr., Dolbeer, R.A., 2009. Habitat and bird communities at small airports in the midwestern USA. Proc. Wildlife Damage Manage. C., pp 137145. 
DeVault, T.L., Seamans, T.W., Schmidt, J.A., Belant, J.L., Blackwell, B.F., Mooers, N., Tyson, L.A., Van Pelt, L., 2014. Bird use of solar photovoltaic installations at US airports: implications for aviation safety. Landscape Urban Plan. 122,122-128.

Devereux, C.L., McKeever, C.U., Benton, T.G., Whittingham, M.J, 2004. The effect of sward height and drainage on Common Starlings Sturnus vulgaris and Northern Lapwings Vanellus vanellus foraging in grassland habitats. Ibis 146: 115-122.

Dolbeer, R.A., 1990. Ornithology and integrated pest management: Red-winged Blackbirds Agelaius phoeniceus and corn. Ibis 132, 309-322.

Dolbeer, R.A., 2013. The history of wildlife strikes and management at airports. In: DeVault, T.L., Blackwell, B.F., Belant, J.L. (Eds.), Wildlife in airport environments: preventing animal-aircraft collisions through science-based management. The John Hopkins University Press, Baltimore, Maryland, pp. 1-6.

Dolbeer, R.A., Woronecki, P.P., Stickley Jr, A.R., White, S.B., 1978. Agricultural impact of a winter population of blackbirds and starlings. Wilson Bull., 31-44.

Dolbeer, R.A., Wright, S.E., 2009. Safety management systems: how useful will the FAA National Wildlife Strike Database be? Hum. Wildlife Con. 3, 167-178.

Dolbeer, R.A., Wright, S.E., Weller, J., Anderson, A.L., Beiger, M.J., 2015. Wildlife strikes to civil aircraft in the United States, 1990-2014. Serial Report 21. U. S. Department of Transportation, Federal Aviation Administration, Office of Airport Safety and Standards, Washington, D. C., USA.

Donald, P.F., Forrest, C., 1995. The effects of agricultural change on population size of Corn buntings Miliaria calandra on individual farms. Bird Study 42, 205-215. 
475 Federal Aviation Administration, 2007. Hazardous wildlife attractants on or near airports.

476 Advisory Circular 150/5200-33B. U. S. Department of Transportation, Washington, D. C.

477 Federal Aviation Administration, 2009. Hazardous wildlife attractants on or near airports.

478 Advisory Circular, AC 150/5200-33B. Airport Safety and Operations Division AA2-300.

479 U. S. Department of Transportation, Washington, D. C.

480 Fernández-Juricic, E., Siller, S., Kacelnik, A., 2004. Flock density, social foraging, and scanning:

481 an experiment with starlings. Behav. Ecol.1, 371-379.

482 Fischl, J., Caccamise, D. F., 1985. Influence of habitat and season on foraging flock

483 composition in the European Starling (Sturnus vulgaris). Oecologia 67, 532-539.

484 Frawley, B.J., 1989. The dynamics of nongame bird breeding ecology in Iowa alfalfa fields.

485 Iowa State University, Ames, Iowa, USA, p. 94.

486 Frederick, R.B., Klaas, E.E., 1982. Resource use and behavior of migrating snow geese. The J.

487 Wildlife Manage. 46, 601-614.

488 Galle, A.M., Linz, G.M., Homan, H.J., Bleier, W.J., 2009. Avian use of harvested crop fields in

489 North Dakota during spring migration. West. N. Am. Nat. 69, 491-500.

490 Gillings, S., Newson, S.E., Noble, D.G., Vickery, J.A., 2005. Winter availability of cereal

491 stubbles attracts declining farmland birds and positively influences breeding population

492 trends. P. R. Soc. B. 272, 733-739.

493 Gliem, J.A., Holmes, R.G., Wood, R.K., 1990. Corn and soybean harvesting losses. Paper-

$494 \quad$ American Society of Agricultural Engineers.

495 Hamilton Iii, W.J., Gilbert, W.M., 1969. Starling dispersal from a winter roost. Ecology, 886-

$496 \quad 898$. 
Jorgensen, J.G., McCarty, J.P., Wolfenbarger, L.L. 2009. Killdeer Charadrius vociferous breeding abundance and habitat use in the Eastern Rainwater Basin, Nebraska. Wader Study Group Bull. 116(2), 1-4.

Killpak, M.L., Crittenden, D.N., 1952. Starlings as winter residents of the Unita Basin, Utah. Condor 54, 338-343.

Kopij, G., 2008. Effect of change in land use on breeding bird communities in a Silesian farmland (SW Poland). P. J. Ecol. 56, 511-519.

Kragten, S., de Snoo, G.R., 2008. Field-breeding birds on organic and conventional arable farms in the Netherlands. Agr. Ecosyst. Environ.126, 270-274.

Krapu, G.L., Brandt, D.A., Cox Jr, R.R., 2004. Less waste corn, more land in soybeans, and the switch to genetically modified crops: trends with important implications for wildlife management. Wildlife S. Bull. 32, 127-136.

Krapu, G.L., Brandt, D.A., Cox, J., R.R., 2005. Do arctic-nesting species compete with sandhill cranes for waste corn in the central Platte river valley, Nebraska? Proc. North American Crane Workshop 9, 185-191.

Krapu, G.L., Reinecke, K.J., Jorde, D.G., Simpson, S.G., 1995. Spring-staging ecology of midcontinent greater white-fronted geese. J. Wildlife Manage., 736-746.

Kuzmenko, T.M., 2012. Bird distribution in biotopes of open agricultural lands in breeding season. Vestn. Z. 46, e-41 - e-44.

Linz, G.M., Homan, H.J., Gaulker, S.M., Penry, L.B., Bleier, W.J., 2007. European starlings: a review of an invasive species with far-reaching impacts. Managing Vertebr. Invasive Species, 24. 
Martin, J.A., Belant, J.L., DeVault, T.L., L. W. Burger, J., Blackwell, B.F., Riffell, S.K., Wang, G., 2011. Wildlife risk to aviation: a multi-scale issue requires a multi-scale solution. Hum. Wildlife Interact. 5, 198-203.

Martin, J.A., Conkling, T.J., Belant, J.L., Biondi, K.M., Blackwell, B.F., DeVault, T.L., Fernández-Juricic, E., Schmidt, P.M., Seamans, T.W., 2013. Wildlife conservation and alternative land uses at airports, in: DeVault, T.L., Blackwell, B.F., Belant, J.L. (Eds.), Wildlife in airport environments: preventing animal-aircraft collisions through science-

Mead, H., Carter, A.W., 1973. The management of long grass as a bird repellent on airfields. Grass Forage Sci.28, 219-221.

Moorcroft, D., Whittingham, M.J., Bradbury, R.B., Wilson, J.D., 2002. The selection of stubble fields by wintering granivorous birds reflects vegetation cover and food abundance. J. Appl. Ecol. 39, 535-547.

Morrison, D.W., Caccamise, D.F., 1990. Comparison of roost use by three species of communal roostmates. Condor, 405-412.

Oksanen, J., 2014. Multivariate analysis of ecological communities in R: vegan tutorial. http://cc.oulu.fi/ jarioksa/softhelp/vegan.html (accessed 17.04.15).

Ott, L.R., Longnecker, M., 2010. An introduction to statistical methods and data analysis. Brooks

Peterjohn, B.G., 1989. The birds of Ohio. Indiana University Press, Bloomington, Indiana, USA. and Cole, Duxbury Pacific Grove, California.

R Core Team. 2015. R: a language and environment for statistical computing. R Foundation for 
542 Rodenhouse, N.L., Best, L.B., 1983. Breeding ecology of vesper sparrows in corn and soybean $543 \quad$ fields. Am. Midl. Nat. 110, 265-275.

544 Rodenhouse, N.L., Best, L.B., O'Connor, R.J., Bollinger, E.K., 1993. Effects of temperate

Status and management of neotropical migratory birds. U. S. Forest Service General Technical Report RM-229 Rocky Mountain Forest and Range Experimental Station, Fort Collins, Colorado, USA, pp. 280-294.

Royle, J.A., Dawson, D.K., Bates, S., 2004. Modeling abundance effects in distance sampling. Ecology 85, 1591-1597.

Sawin, R.S., Linz, G.M., Bleier, W.J., Homan, H.J., 2006. Feeding habitats of spring-migrating blackbirds in east-central South Dakota. Prairie Nat. 38, 73.

Seamans, T.W., Barras, S.C., Bernhardt, G.E., Blackwell, B.F., Cepek, J.D., 2007. Comparison of 2 vegetation-height management practices for wildlife control at airports. Hum. Wildlife Con. 1, 97-105.

Seamans, T.W., Dolbeer, W.A., Carrara, M.S., Chipman, R.B., 1999. Does tall grass reduce bird numbers on airports? Results of pen test with Canada geese and field trials at two airports, 1998. 1999 Bird Strike Committee-USA/Canada, First Joint Annual Meeting, Vancouver, British Columbia, Canada, pp. 160-170.

Sterner, R.T., Elias, D.J., Garrison, M.V., Johns, B.E., Kilburn, S.R., 1984. Birds and airport agriculture in the conterminous United States: a review of literature. Office of Airport Standards, Wildlife Hazards to Aircraft C. and Training Workshop. DOT/FAA/AAS. US Department of Transportation, Washington, D. C. 
564 Thomas, L., Buckland, S.T., Rexstad, E.A., Laake, J.L., Strindberg, S., Hedley, S.L., Bishop, 565 J.R.B., Marques, T.A., Burnham, K.P., 2010. Distance software: design and analysis of 566 distance sampling surveys for estimating population size. J. Appl. Ecol. 47, 5-14.

567 Transport Canada, 1994. Wildlife control procedures manual. Environmental and Support 568

569 VanBeek, K.R., Brawn, J.D., Ward, M.P., 2014. Does no-till soybean farming provide any 570 benefits for birds? Agric. Ecosyst. Environ. 185, 59-64.

571 Washburn, B.E., Seamans, T.W., 2004. Management of vegetation to reduce wildlife hazards at airports. FAA Worldwide Airport Technology Transfer C., Atlantic City, New Jersey, pp.

574 Whittingham, M.J. \& Devereux, C.L, 2008. Changing grass height alters foraging site selection 575 by wintering farmland birds. Basic Appl. Ecol. 9:779-788.

576 Williams, R.E., Jackson, W.B., 1981. Dietary comparisons of red-winged blackbirds, brown577 headed cowbirds, and European starlings in north-central Ohio. Ohio J. of Science 81,

579 Wilson, J.D., Taylor, R., Muirhead, L.B., 1996. Field use by farmland birds in winter: an analysis of field type preferences using resampling methods. Bird Study 43, 320-332.

581 Yasukawa, K., Searcy, W.A., 1995. Red-winged blackbird: Agelaius phoeniceus. Birds North 582 Am. 184, 1-28. 
Table 1. Body lengths of ground foraging bird species observed within effective distance radii of the observer during point transects of corn, soybean, and wheat fields near Oak Harbor, OH, visited weekly from June 2013- March 2014. Number of detections represents how many observations included at least 1 bird per species, not the number of species observed, within effective distance radii of the observer. Hazard levels per species were developed based on the percentage of recorded strikes with aircraft causing damage [Dolbeer and Wright, 2009; very high $(20 \% \leq x<40 \%$ of strikes causing damage) and extremely high ( $\geq 40 \%$ strikes causing damage) hazard levels were combined for analysis (e.g., VE High)].

\begin{tabular}{lcccc}
\hline \multicolumn{1}{c}{ Species } & & Number of & \multicolumn{2}{c}{ Body Length (cm) } \\
\cline { 4 - 5 } American goldfinch & Hazard Level & Detections & Range & Average \\
American pipit & Low & 1 & $11-13$ & 12.0 \\
American robin & Low & 1 & $14-17$ & 15.5 \\
Brown-headed cowbird & High & 27 & $20-28$ & 24.0 \\
Bobolink & Low & 1 & $19-22$ & 20.5 \\
Canada goose & Low & 1 & $15-21$ & 18.0 \\
Chipping sparrow & Extremely High & 1 & $76-110$ & 93.0 \\
Common grackle & Low & 2 & $12-15$ & 13.5 \\
Eastern bluebird & High & 25 & $28-34$ & 31.0 \\
Eastern meadowlark & Low & 1 & $16-21$ & 18.5 \\
European starling & Low & 1 & $19-26$ & 22.5 \\
Field sparrow & Medium & 15 & $20-23$ & 21.5 \\
Horned lark & Low & 1 & $12-15$ & 13.5 \\
House sparrow & Low & 167 & $16-20$ & 18.0 \\
Indigo bunting & Medium & 5 & $15-17$ & 16.0 \\
Inca dove & Low & 1 & $12-13$ & 12.5 \\
Killdeer & Low & 2 & $18-23$ & 20.5 \\
Lapland longspur & Low & 75 & $20-28$ & 24.0 \\
Mourning dove & Low & 2 & $15-16$ & 15.5 \\
Red-winged blackbird & Medium & 12 & $23-34$ & 28.5 \\
Savannah sparrow & Medium & 90 & $17-23$ & 20.0 \\
Song sparrow & Low & 6 & $11-15$ & 13.0 \\
\hline & Low & 7 & $12-17$ & 14.5 \\
\hline
\end{tabular}


Table 2. Model selection results regarding distance analysis of bird hazard category responses to crop type and height categories from point transects conducted near Oak Harbor, OH, June 2013- March 2014. Crop height categories were based on bird line-of-sight of 22 ground foraging species.

\begin{tabular}{|c|c|c|c|c|c|c|c|c|}
\hline $\begin{array}{c}\text { Hazard } \\
\text { Category }\end{array}$ & Model $^{1}$ & $\mathrm{k}$ & AICc & $\triangle \mathrm{AICc}$ & $\begin{array}{c}\text { AICc } \\
\text { Weight }\end{array}$ & $\begin{array}{c}\text { Cumulative } \\
\text { Weight }\end{array}$ & $\begin{array}{c}\text { Log- } \\
\text { Likelihood }\end{array}$ & $\begin{array}{c}\text { Evidence } \\
\text { Ratio }\end{array}$ \\
\hline \multirow[t]{4}{*}{ Low } & Crop_Height; 1; Crop_Height & 11 & 1776.55 & 0.00 & 0.73 & 0.73 & -876.61 & 1.00 \\
\hline & $\sim$ Crop_Type + Crop_Height; $\sim 1 ; \sim$ Crop_Height & 13 & 1779.18 & 2.62 & 0.20 & 0.93 & -875.66 & 3.71 \\
\hline & Crop_Type; $\sim 1 ;$ Crop_Height & 10 & 1782.29 & 5.73 & 0.04 & 0.97 & -880.59 & 17.57 \\
\hline & $\sim 1 ; \sim 1 ; \sim$ Crop_Height & 8 & 1783.20 & 6.65 & 0.03 & 1.00 & -883.24 & 27.79 \\
\hline \multirow[t]{4}{*}{ Medium } & $\sim$ Crop_Type + Crop_Height; $\sim$ Month; $\sim$ Crop_Height & 14 & 696.26 & 0.00 & 0.85 & 0.85 & -333.05 & 1.00 \\
\hline & $\sim$ Crop_Height; $\sim$ Month; $\sim$ Crop_Height & 12 & 699.68 & 3.42 & 0.15 & 1.00 & -337.05 & 5.53 \\
\hline & Crop_Type; Month; Crop_Height & 11 & 709.67 & 13.41 & 0.00 & 1.00 & -343.17 & 816.56 \\
\hline & 1; Month; Crop_Height & 9 & 715.09 & 18.83 & 0.00 & 1.00 & -348.09 & 12245.11 \\
\hline \multirow[t]{4}{*}{ High } & Crop_Height; Month; Crop_Height & 12 & 437.15 & 0.00 & 0.89 & 0.89 & -205.78 & 1.00 \\
\hline & Crop_Type + Crop_Height; Month; Crop_Height & 14 & 441.35 & 4.19 & 0.11 & 1.00 & -205.60 & 8.14 \\
\hline & 1; Month; Crop_Height & 8 & 453.51 & 16.36 & 0.00 & 1.00 & -218.40 & 3563.43 \\
\hline & Crop_Type; Month; Crop_Height & 10 & 456.15 & 19.00 & 0.00 & 1.00 & -217.52 & 13371.90 \\
\hline \multirow[t]{4}{*}{ VE High } & Crop_Height; Month; Crop_Height & 12 & 328.39 & 0.00 & 0.59 & 0.59 & -151.40 & 1.00 \\
\hline & 1; Month; Crop_Height & 9 & 329.94 & 1.55 & 0.27 & 0.86 & -155.52 & 2.17 \\
\hline & Crop_Type; Month; Crop_Height & 11 & 332.56 & 4.17 & 0.07 & 0.94 & -154.61 & 8.03 \\
\hline & Crop_Type + Crop_Height; Month; & 14 & 332.81 & 4.41 & 0.06 & 1.00 & -151.33 & 9.09 \\
\hline
\end{tabular}

$585 \quad$ Detection models are displayed as 3 right-sided formulas for abundance, availability, and detection covariates 
Table 3. Model selection results regarding distance analysis of bird hazard category responses to crop type and height categories from point transects conducted near Oak Harbor, OH, June 2013- March 2014. Crop-height categories were based on past studies regarding airfield grassland management.

\begin{tabular}{|c|c|c|c|c|c|c|c|c|}
\hline $\begin{array}{c}\text { Hazard } \\
\text { Category }\end{array}$ & Model $^{1}$ & $\mathrm{k}$ & AICc & $\triangle \mathrm{AICc}$ & $\begin{array}{c}\text { AICc } \\
\text { Weight }\end{array}$ & $\begin{array}{c}\text { Cumulative } \\
\text { Weight }\end{array}$ & $\begin{array}{c}\text { Log- } \\
\text { Likelihood }\end{array}$ & $\begin{array}{c}\text { Evidence } \\
\text { Ratio }\end{array}$ \\
\hline \multirow{4}{*}{ Low } & $\sim$ Crop_Height, $\sim 1, \sim$ Crop_Height & 13 & 1783.05 & 0.00 & 0.60 & 0.60 & -877.60 & 1.00 \\
\hline & 〜Crop_Type, $\sim 1, \sim$ Crop_Height & 11 & 1785.65 & 2.60 & 0.16 & 0.76 & -881.16 & 3.67 \\
\hline & $\sim$ Crop_Type + Crop_Height, $\sim 1, \sim$ Crop_Height & 15 & 1786.07 & 3.03 & 0.13 & 0.90 & -876.80 & 4.54 \\
\hline & $\sim 1, \sim 1, \sim$ Crop_Height & 9 & 1786.56 & 3.51 & 0.10 & 1.00 & -883.83 & 5.78 \\
\hline \multirow[t]{4}{*}{ Medium } & $\sim$ Crop_Type + Crop_Height, $\sim 1, \sim$ Crop_Height & 15 & 699.63 & 0.00 & 0.97 & 0.97 & -333.58 & 1.00 \\
\hline & $\sim$ Crop_Height, $\sim 1, \sim$ Crop_Height & 13 & 706.70 & 7.07 & 0.03 & 1.00 & -339.42 & 34.30 \\
\hline & $\sim$ Crop_Type, $\sim 1, \sim$ Crop_Height & 11 & 718.83 & 19.21 & 0.00 & 1.00 & -347.75 & 14804.78 \\
\hline & $\sim 1, \sim 1, \sim$ Crop_Height & 9 & 723.87 & 24.25 & 0.00 & 1.00 & -352.49 & 184046.73 \\
\hline \multirow[t]{4}{*}{ High } & $\sim$ Crop_Height, $\sim$ Month, $\sim$ Crop_Height & 14 & 433.54 & 0.00 & 0.66 & 0.66 & -201.69 & 1.00 \\
\hline & $\sim$ Crop_Type + Crop_Height, $\sim$ Month, $\sim$ Crop_Height & 16 & 434.87 & 1.33 & 0.34 & 1.00 & -200.02 & 1.94 \\
\hline & $\sim 1, \sim$ Month, $\sim$ Crop_Height & 10 & 445.38 & 11.84 & 0.00 & 1.00 & -212.14 & 371.74 \\
\hline & $\sim$ Crop_Type, $\sim$ Month, $\sim$ Crop_Height & 12 & 448.32 & 14.78 & 0.00 & 1.00 & -211.37 & 1623.02 \\
\hline \multirow[t]{4}{*}{ VE High } & $\sim 1, \sim 1, \sim 1$ & 3 & 426.99 & 0.00 & 0.43 & 0.43 & -210.44 & 1.00 \\
\hline & $\sim$ Crop_Height, $\sim 1, \sim 1$ & 7 & 427.24 & 0.25 & 0.38 & 0.82 & -206.34 & 1.13 \\
\hline & 〜Crop_Type, $\sim 1, \sim 1$ & 5 & 429.53 & 2.53 & 0.12 & 0.94 & -209.62 & 3.55 \\
\hline & $\sim$ Crop_Type + Crop_Height, $\sim$ Month, $\sim$ Crop_Height & 9 & 430.96 & 3.97 & 0.06 & 1.00 & -206.03 & 7.27 \\
\hline
\end{tabular}

587 Detection models are displayed as 3 right-sided formulas for abundance, availability, and detection covariates 
Table 4. Density estimates and 95\% confidence intervals (CI) for bird species observed using point transects among agricultural fields near Oak Harbor, OH, June 2013 - March 2014. Crop height classification was based on lengths of 22 observed ground foragers. Birds were categorized by hazard categories (see text for methods).

\begin{tabular}{|c|c|c|c|c|c|c|c|c|c|}
\hline \multirow[b]{3}{*}{ Crop } & \multirow[b]{3}{*}{ Height } & \multicolumn{8}{|c|}{ Hazard Category } \\
\hline & & \multicolumn{2}{|r|}{ Low } & \multicolumn{2}{|c|}{ Medium } & \multicolumn{2}{|r|}{ High } & \multicolumn{2}{|c|}{ VE High } \\
\hline & & $\bar{x}$ & CI & $\bar{x}$ & $\mathrm{CI}$ & $\bar{x}$ & CI & $\bar{x}$ & CI \\
\hline \multirow[t]{4}{*}{ corn } & Stubble & 0.249 & $0.166-0.377$ & 0.013 & $0.004-0.058$ & 0.017 & $0.005-0.064$ & 0.014 & $0.004-0.053$ \\
\hline & $0-15 \mathrm{~cm}$ & 0.413 & $0.262-0.660$ & 0.046 & $0.011-0.225$ & 0.086 & $0.026-0.322$ & 0.058 & $0.016-0.248$ \\
\hline & $>15-32 \mathrm{~cm}$ & 0.254 & $0.151-0.433$ & 0.068 & $0.020-0.299$ & 0.119 & $0.038-0.416$ & 0.022 & $0.006-0.112$ \\
\hline & $>32 \mathrm{~cm}$ & 0.125 & $0.060-0.263$ & 0.085 & $0.031-0.235$ & 0.154 & $0.049-0.482$ & 0.012 & $0.003-0.086$ \\
\hline \multirow[t]{4}{*}{ soybean } & Stubble & 0.277 & $0.195-0.393$ & 0.020 & $0.009-0.042$ & 0.017 & $0.005-0.055$ & 0.016 & $0.005-0.048$ \\
\hline & $0-15 \mathrm{~cm}$ & 0.456 & $0.305-0.684$ & 0.069 & $0.031-0.156$ & 0.085 & $0.028-0.262$ & 0.060 & $0.019-0.194$ \\
\hline & $>15-32 \mathrm{~cm}$ & 0.283 & $0.177-0.453$ & 0.099 & $0.044-0.223$ & 0.117 & $0.040-0.342$ & 0.024 & $0.007-0.095$ \\
\hline & $>32 \mathrm{~cm}$ & 0.143 & $0.070-0.300$ & 0.133 & $0.027-0.680$ & 0.152 & $0.045-0.549$ & 0.013 & $0.003-0.094$ \\
\hline \multirow[t]{4}{*}{ wheat } & Stubble & 0.266 & $0.185-0.383$ & 0.047 & $0.022-0.098$ & 0.018 & $0.006-0.057$ & 0.015 & $0.005-0.046$ \\
\hline & $0-15 \mathrm{~cm}$ & 0.439 & $0.289-0.667$ & 0.166 & $0.065-0.423$ & 0.089 & $0.028-0.278$ & 0.058 & $0.017-0.198$ \\
\hline & $>15-32 \mathrm{~cm}$ & 0.271 & $0.168-0.439$ & 0.225 & $0.115-0.440$ & 0.122 & $0.042-0.356$ & 0.023 & $0.006-0.089$ \\
\hline & $>32 \mathrm{~cm}$ & - & - & - & - & - & - & - & - \\
\hline
\end{tabular}


Table 5. Density estimates and 95\% confidence intervals (CI) for bird species observed using point transects among agricultural fields near Oak Harbor, OH, June 2013 - March 2014. Crop height classification was based on past research investigating bird response to airport grassland management. Birds were categorized by hazard categories (see text in methods.

\begin{tabular}{|c|c|c|c|c|c|c|c|c|c|}
\hline \multirow[b]{3}{*}{ Crop } & \multirow[b]{3}{*}{ Height } & \multicolumn{8}{|c|}{ Hazard Category } \\
\hline & & \multicolumn{2}{|r|}{ Low } & \multicolumn{2}{|r|}{ Medium } & \multicolumn{2}{|r|}{ High } & \multicolumn{2}{|c|}{ VE High } \\
\hline & & $\bar{x}$ & $\mathrm{CI}$ & $\bar{x}$ & $\mathrm{CI}$ & $\bar{x}$ & $\mathrm{CI}$ & $\bar{x}$ & $\mathrm{CI}$ \\
\hline \multirow[t]{5}{*}{ corn } & Stubble & 0.244 & $0.162-0.373$ & 0.001 & $0.000-8.209 E+13$ & 0.010 & $0.003-1.048 E+65$ & 0.020 & $0.007-0.070$ \\
\hline & $0-15 \mathrm{~cm}$ & 0.385 & $0.244-0.615$ & 0.002 & $0.001-2.784 E+14$ & 0.051 & $0.016-5.031 E+65$ & 0.050 & $0.015-0.204$ \\
\hline & $>15-25 \mathrm{~cm}$ & 0.255 & $0.140-0.473$ & 0.001 & $0.000-1.934 E+14$ & 0.046 & $0.012-5.040 \mathrm{E}+65$ & 0.017 & $0.005-0.096$ \\
\hline & $>25-45 \mathrm{~cm}$ & - & - & - & - & - & - & - & - \\
\hline & $>45 \mathrm{~cm}$ & 0.135 & $0.064-0.299$ & 0.132 & $0.045-0.386$ & 0.221 & $0.068-0.721$ & 0.020 & $0.005-0.130$ \\
\hline \multirow[t]{5}{*}{ soybean } & Stubble & 0.282 & $0.200-0.398$ & 0.023 & $0.011-0.048$ & 0.017 & $0.005-0.057$ & 0.023 & $0.008-0.066$ \\
\hline & $0-15 \mathrm{~cm}$ & 0.434 & $0.293-0.645$ & 0.076 & $0.034-0.170$ & 0.087 & $0.027-0.275$ & 0.056 & $0.019-0.167$ \\
\hline & $>15-25 \mathrm{~cm}$ & 0.293 & $0.173-0.505$ & 0.053 & $0.017-0.160$ & 0.082 & $0.020-0.328$ & 0.021 & $0.007-0.093$ \\
\hline & $>25-45 \mathrm{~cm}$ & 0.256 & $0.154-0.433$ & 0.123 & $0.049-0.308$ & 0.107 & $0.031-0.375$ & 0.035 & $0.010-0.144$ \\
\hline & $>45 \mathrm{~cm}$ & - & - & - & - & - & - & - & - \\
\hline \multirow[t]{5}{*}{ wheat } & Stubble & 0.271 & $0.189-0.390$ & 0.049 & $0.024-0.103$ & 0.019 & $0.006-0.064$ & 0.021 & $0.007-0.062$ \\
\hline & $0-15 \mathrm{~cm}$ & 0.420 & $0.279-0.634$ & 0.167 & $0.067-0.417$ & 0.094 & $0.028-0.316$ & 0.051 & $0.016-0.164$ \\
\hline & $>15-25 \mathrm{~cm}$ & 0.283 & $0.162-0.500$ & 0.115 & $0.035-0.376$ & 0.090 & $0.020-0.399$ & 0.019 & $0.006-0.089$ \\
\hline & $>25-45 \mathrm{~cm}$ & 0.246 & $0.146-0.419$ & 0.268 & $0.132-0.545$ & 0.116 & $0.035-0.390$ & 0.032 & $0.009-0.126$ \\
\hline & $>45 \mathrm{~cm}$ & - & - & - & - & - & - & - & - \\
\hline
\end{tabular}


Table 6. Bird community responses to 3 crops and 2 crop-height classifications (bird body length and airport-based research on bird use of different grass heights) from weekly point transects conducted near Oak Harbor, OH, June 2013 - March 2014.

\begin{tabular}{|c|c|c|c|c|c|c|}
\hline Comparison & $\mathrm{df}$ & $\mathrm{SS}^{1}$ & $\mathrm{MSE}^{2}$ & $F$ & $\begin{array}{c}\text { Partial } \\
\mathrm{R}^{2}\end{array}$ & $P$-value ${ }^{3}$ \\
\hline Corn vs. Soybean & 2 & 2.487 & 1.243 & 2.894 & 0.022 & 0.001 \\
\hline Corn vs. Wheat & 2 & 2.487 & 1.243 & 2.894 & 0.022 & 0.001 \\
\hline Soybean vs. Wheat & 2 & 2.487 & 1.243 & 2.894 & 0.022 & 0.001 \\
\hline Stubble vs. $0-15 \mathrm{~cm}$ & 2 & 7.215 & 3.608 & 8.781 & 0.064 & 0.001 \\
\hline Stubble vs. $>15-25 \mathrm{~cm}$ & 2 & 5.195 & 2.598 & 6.202 & 0.046 & 0.001 \\
\hline Stubble vs. $>25-45 \mathrm{~cm}$ & 2 & 6.614 & 3.307 & 8.003 & 0.059 & 0.001 \\
\hline Stubble vs. $>45 \mathrm{~cm}$ & 2 & 5.817 & 2.908 & 6.985 & 0.052 & 0.001 \\
\hline $0-15 \mathrm{~cm}$ vs. $>15-25 \mathrm{~cm}$ & 2 & 1.913 & 0.956 & 2.214 & 0.017 & 0.004 \\
\hline $0-15 \mathrm{~cm}$ vs. $>25-45 \mathrm{~cm}$ & 2 & 4.523 & 2.261 & 5.365 & 0.040 & 0.001 \\
\hline $0-15 \mathrm{~cm}$ vs. $>45 \mathrm{~cm}$ & 2 & 2.946 & 1.473 & 3.444 & 0.026 & 0.001 \\
\hline$>15-25 \mathrm{~cm}$ vs. $>25-45 \mathrm{~cm}$ & 2 & 5.428 & 2.714 & 6.494 & 0.048 & 0.001 \\
\hline$>15-25 \mathrm{~cm}$ vs. $>45 \mathrm{~cm}$ & 2 & 3.835 & 1.918 & 4.520 & 0.034 & 0.001 \\
\hline$>25-45 \mathrm{~cm}$ vs. $>45 \mathrm{~cm}$ & 2 & 6.809 & 3.405 & 8.254 & 0.061 & 0.001 \\
\hline Stubble vs. $0-15 \mathrm{~cm}$ & 2 & 7.215 & 3.608 & 8.781 & 0.064 & 0.001 \\
\hline Stubble vs. $>15-32 \mathrm{~cm}$ & 2 & 5.543 & 2.771 & 6.638 & 0.049 & 0.001 \\
\hline Stubble vs. $>32 \mathrm{~cm}$ & 2 & 5.801 & 2.901 & 6.965 & 0.052 & 0.001 \\
\hline $0-15 \mathrm{~cm}$ vs. $>15-32 \mathrm{~cm}$ & 2 & 3.892 & 1.946 & 4.589 & 0.035 & 0.001 \\
\hline $0-15 \mathrm{~cm}$ vs. $>32 \mathrm{~cm}$ & 2 & 3.232 & 1.616 & 3.788 & 0.029 & 0.001 \\
\hline$>15-32 \mathrm{~cm}$ vs. $<32 \mathrm{~cm}$ & 2 & 7.025 & 3.513 & 8.534 & 0.063 & 0.001 \\
\hline \multicolumn{7}{|l|}{${ }^{1}$ Sum of Squares (SS) } \\
\hline${ }^{2}$ Mean Square Error (MSE) & & & & & & \\
\hline
\end{tabular}


Table 7. Diversity metrics among crops and crop-height classifications by visit of observed bird communities in agricultural fields near Oak Harbor, OH, June 2013 - March 2014. Crop heights were classified by past airport grassland literature and bird body lengths.

\begin{tabular}{ccccccc}
\hline & \multicolumn{2}{c}{$\begin{array}{c}\text { Species } \\
\text { Richness }\end{array}$} & \multicolumn{2}{c}{$\begin{array}{c}\text { Shannon's } \\
\text { Diversity }\end{array}$} & \multicolumn{2}{c}{$\begin{array}{c}\text { Cumulative } \\
\text { Hazard Score }\end{array}$} \\
\hline & $\bar{x}$ & SE & $\bar{x}$ & SE & $\bar{x}$ & SE \\
\hline Crops & & & & & & \\
Corn & 0.43 & 0.07 & 0.04 & 0.02 & 77.61 & 49.93 \\
Soybean & 0.53 & 0.05 & 0.08 & 0.01 & 122.83 & 37.25 \\
Wheat & 0.72 & 0.07 & 0.12 & 0.02 & 245.52 & 80.64
\end{tabular}

Crop Height

$\begin{array}{rrlllll}\text { Stubble } & 1.34 & 0.06 & 0.16 & 0.03 & 170.27 & 54.08 \\ 0-15 \mathrm{~cm}^{1 ; 2} & 1.68 & 0.12 & 0.34 & 0.06 & 148.68 & 88.71 \\ >15-32 \mathrm{~cm}^{1} & 1.54 & 0.11 & 0.25 & 0.05 & 132.40 & 46.48 \\ >32 \mathrm{~cm}^{1} & 1.25 & 0.09 & 0.14 & 0.05 & 251.25 & 159.66 \\ & & & & & & \\ >15-25 \mathrm{~cm}^{2} & 1.27 & 0.11 & 0.13 & 0.05 & 90.20 & 42.46 \\ >25-45 \mathrm{~cm}^{2} & 1.67 & 0.15 & 0.30 & 0.06 & 240.31 & 105.83 \\ >45 \mathrm{~cm}^{2} & 1.32 & 0.11 & 0.17 & 0.06 & 110.63 & 86.42\end{array}$
bird use of grass areas. 
598 Figure 1. Site distribution map of 22 agricultural fields sampled for birds using point transects

599 near Oak Harbor, OH, from June 2013 to March 2014.

600

601 Figure 2. Average species richness, Shannon's diversity, and cumulative bird hazard scores

602 among crop heights of bird communities in agricultural fields near Oak Harbor, OH, June 2013

603 to March 2014 observed using point transects. Crop-height bins were derived from airport-based

604 research regarding airport grassland management for bird strike mitigation or bird body lengths. 
Figure 1.

606

607

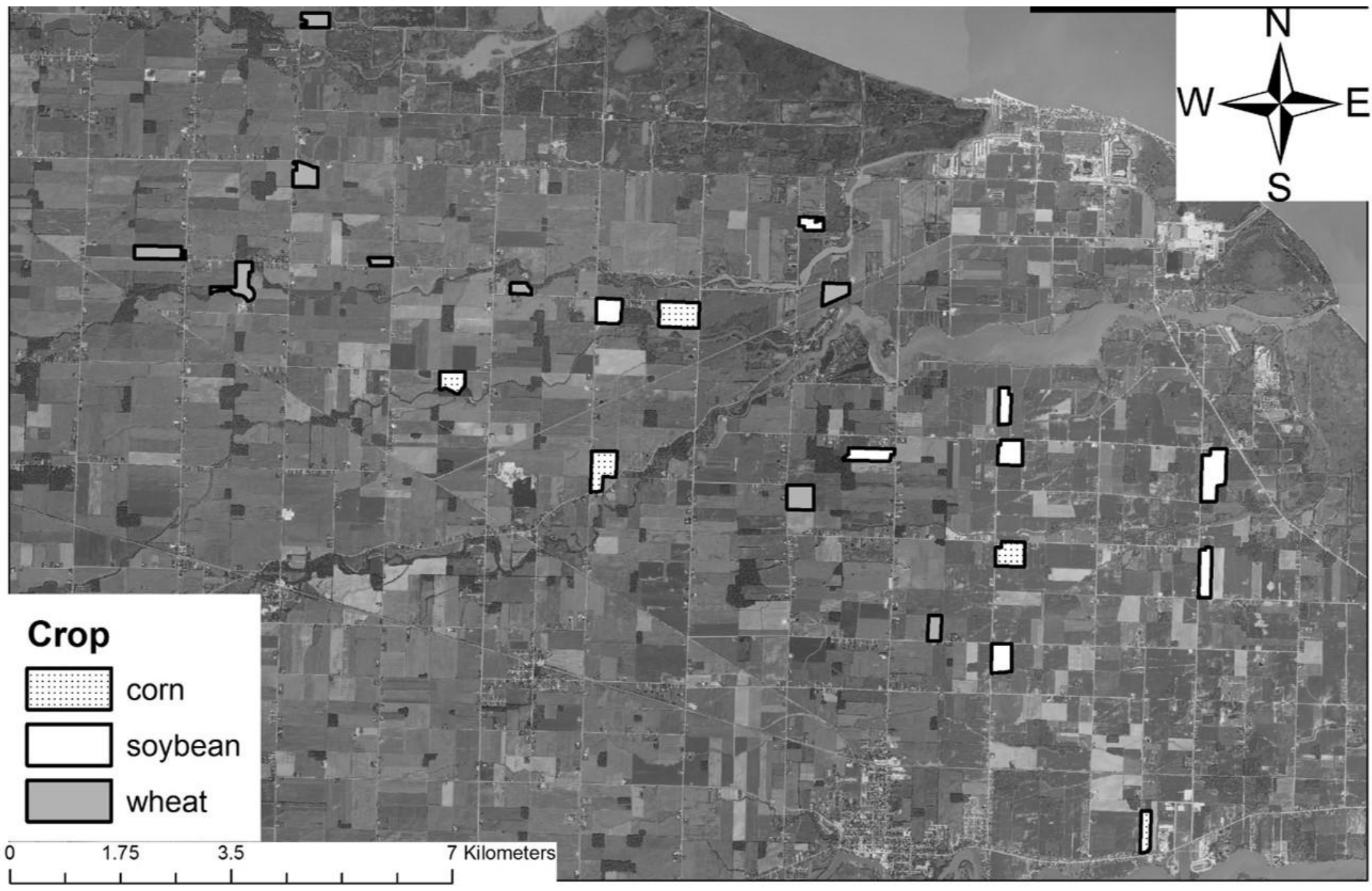


608 Figure 2.

609

$\square$ Soybean $\quad$ Corn $\square$ Wheat
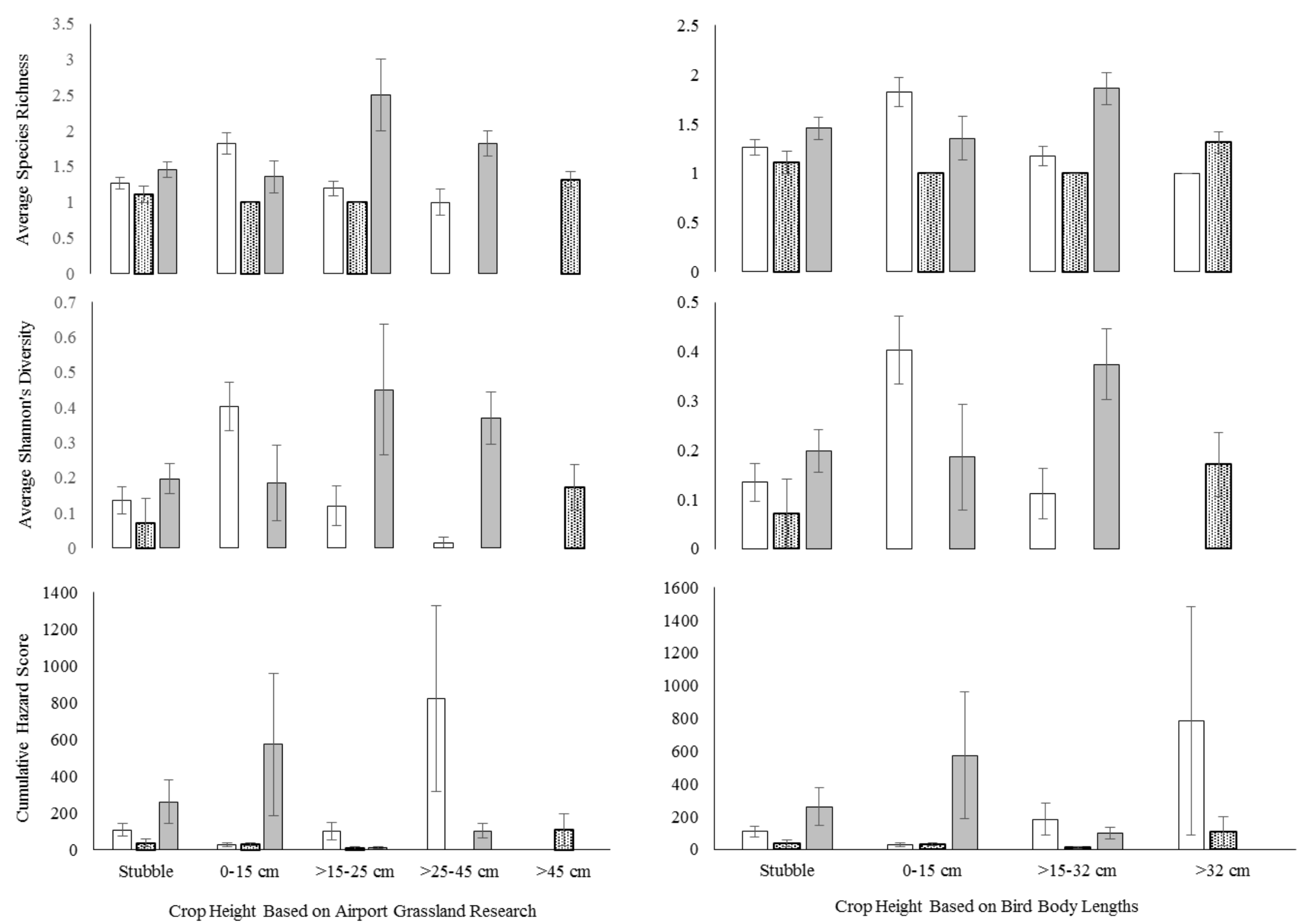